\title{
AUTORES DEL NÚMERO ESPECIAL
}

\section{JOCELYN BENOIST}

Profesor de filosofía contemporánea y filosofía del conocimiento la Universidad de París 1 (Panthéon-Sorbonne). El año 2000 recibió la Medalla de bronce del Centre national de la recherche scientifique (CNRS). Fue también director de los Archives Husserl de Paris durante los años 2009-2013. Benoist se ha especializado en fenomenología husserliana, la escuela filosofía austriaca, filosofía analítica, filosofía de la mente, filosofía del lenguaje y metafísica. Sus temas actuales de investigación están centrados en el contextualismo, en la filosofía del lenguaje y del espíritu, la relación entre lenguaje y percepción, la filosofía social y el (neo) realismo. Entre sus publicaciones más relevantes podemos mencionar Phénoménologie, sémantique, ontologie: Husserl et la tradition logique autrichienne (P.U.F., 1997), L'a priori conceptuel: Bolzano, Husserl, Schlick (Vrin, 1999), L'idée de phénoménologie (Beauchesne 2001), Représentations sans objet: aux origines de la phénoménologie et de la philosophie analytique (P.U.F., 2001), Les limites de l'intentionalité. Recherches phénoménologiques et analytiques (Vrin, 2005), Sens et sensibilité. L'intentionalité en contexte (Ed. du Cerf, 2009), Concepts. Introduction à l'analyse (Ed. du Cerf, 2010), Éléments de Philosophie Réaliste. Réflexions sur ce que l'on a, (Vrin, 2011), L'adresse du réel (Paris, Vrin, 2017) y Réalismes anciens et nouveaux (Paris, Vrin, 2018).

\section{SYLVAIN CAMILLERI}

Profesor en el Instituto Superior de Filosofia y miembro del Centro de Estudios Fenomenológicos de la Universidad Católica de Lovaina. Obtuvo su doctorado en Filosofía por la Universidad Católica de Lovaina y la Universidad Paul-Valéry Montpellier III (Francia). Sus principales áreas de interés son la fenomenología, hermenéutica, filosofía de la religión, filosofía de la cultura y la filosofía de la historia. Ha publicado las siguientes monografías: Phénoménologie de la religion et herméneutique théologique dans la pensée du jeune Heidegger (Dordrecht: Springer, 2008) y Heidegger et les grandes lignes d'une phénoménologie herméneutique du christianisme primitif(Dordrecht: Springer, 2017).

\section{CARla CANullo}

Profesora de filosofía en la Universidad de Macerata, Italia. Ha sido docente en el Institut Catholique de Paris (2003-2007) y ha impartido seminarios en diversas 
universidades europeas. El centro de su investigación es la fenomenología y la hermenéutica contemporáneas en autores como Maine de Biran, Jean Nabert, Jacques Derrida, Michel Henry o Jean-Luc Marion. Es miembro de la Societé francophone de Philosophie de la religion y del Laboratoire de Phénoménologie et herméneutiques. Ha publicado numerosos artículos en revistas especializadas y colaboraciones en obras colectivas. Es autora de Coscienza e libertà (2001), Male ingiustificabile e metafisica della testimonianza (2002), L'estasi della speranza (2005).

\section{JIMMY HERNÁNDEZ MARCELO}

Estudios de filosofía en la Universidad Pontificia de Salamanca (Grado y Master). Doctor en filosofía por la Universidad de Turín y la Universidad de Salamanca. Ha desarrollado su actividad de investigación en la Universidad de París 1, en la Universidad Católica de Lovaina-la-Nueva, en la Universidad de Coímbra, en los Archivos Husserl de la Universidad de Friburgo, en los Archivos Husserl de la Universidad de Colonia y en la Universidad de Bonn. Su campo de investigación está enfocado en la filosofía francesa contemporánea (fenomenología y epistemología) y en la ontología social (continental y analítica). Es Miembro del Laboratorio de Ontología de la Universidad de Turín (Labont) en donde realiza su investigación post-doctoral bajo la supervisión de Maurizio Ferraris. Ha publicado artículos sobre los orígenes de la fenomenología y sobre filosofía francesa contemporánea. Ha traducido escritos de Jocelyn Benoist, Jean Héring, Sylvain Camilleri, Jacques Derrida entre otros. Es también miembro colaborador del Centro de Estudios Fenomenológicos (CEP) de la Universidad Católica de Lovaina y profesor asociado de la Facultad de Filosofía de la Universidad de Salamanca.

\section{FRANCISCO JAVIER HERRERO HERNÁNDEZ}

Licenciado en Teología Dogmática y Doctor en Filosofía por la Universidad Pontificia de Salamanca con Premio Extraordinario Fin de Carrera y de Doctorado. Ha realizado estudios en Alemania (Freiburg y München) y en Francia (Instituto Católico, Escuela Normal Superior y Sorbona). Es profesor Titular de Teodicea y Filosofía de la Religión de la Facultad de Filosofía de la Universidad Pontificia de Salamanca. También es profesor del Dpto. Historia del Derecho y Filosofía Jurídica, Moral y Política de la Universidad de Salamanca. Ha sido director del Máster de Investigación en Ciencias Humanas y Sociales y de la Cátedra Fernando Rielo. En la actualidad es miembro de la Comisión organizadora de la Cátedra extraordinaria Domingo de Soto (USAL) y de varios Consejos de redacción y Comités científicos de revistas de ámbito filosófico y eclesial. De 2013 a 2018 fue nombrado Experto Asesor de la Agencia de Calidad de la 
Santa Sede (Avepro). Fue también Vicedecano y Decano de la Facultad de Filosofía de la UPSA de 2010 a 2016. Ha dirigido varias Tesis doctorales y participado también en Proyectos de investigación como investigador e investigador principal. Su campo de investigación se centra en las relaciones entre Teología y Filosofía, diálogo Fe y razón, Filosofía de la religión, Teodicea, Fenomenología, Antropología y el pensamiento de Husserl, Heidegger, Rahner, Zubiri, Levinas y Habermas entre otros. Ha publicado numerosos artículos en revistas especializadas y colaboraciones en obras colectivas. Entre sus publicaciones destaca su libro De Husserl a Levinas. Un camino en la fenomenología. (Salamanca: UPSA 2006) y la traducción de la obra de Jean Hering, Fenomenología y filosofía religiosa. Estudio sobre la teoría de la conciencia religiosa. (Madrid: San Dámaso 2019).

\section{CAROLINA LAGOS ORÓSTICA}

Profesora de filosofía en la Universidad Católica de la Santísima Concepción (Chile). Doctoranda e investigadora en la Universidad Pontifica de Salamanca (España). Ha desarrollado su trabajo académico docente e investigativo en la Universidad del Bío Bío y Universidad Católica de la Santísima Concepción principalmente en las áreas de ética, antropología filosófica y filosofía de la religión. Ha publicado artículos relacionados con la filosofía de la religión, cuya problemática ocupa el primer lugar en su trabajo de investigación.

\section{RICARDO MEJÍA FERNÁNDEZ}

Doctor en Lógica y Filosofía de la Ciencia por la Universidad de Salamanca. Máster en Filosofía, Universidad Pontificia de Salamanca. Máster en Lógica y Filosofía de la Ciencia, Universidad de Salamanca. Grado en Filosofía, Universidad Pontificia de Salamanca. Grado en Estudios Eclesiásticos, Ateneo Universitario S. Pacià, Barcelona. Ha sido investigador en el Centro de Estudios Fenomenológicos de la Universidad Católica de Lovaina (Bélgica) y en los Archivos Husserl de la Escuela Normal Superior de Paris (Francia). En la capital francesa ha sido además profesor invitado en la Universidad Panthéon-Sorbonne (Paris 1). En la actualidad es Research Scholar en la Universidad de Memphis (Estados Unidos).

\section{MANUEl PORCEL MORENO}

Profesor de Filosofía de la religión, Teodicea y Fenomenología en la Facultad de Teología de Granada. Se licenció en Estudios Eclesiásticos por la Facultad de Teología de Granada. Posteriormente, realizó sus estudios de filosofía en la Universidad Pontificia de Salamanca, donde obtuvo el Grado en Filosofía y el 
Licenciatus in Philosophia, y en la Universidad de Granada, donde obtuvo el Máster oficial en Filosofía Contemporánea. Obtuvo su doctorado con Mención Internacional en Filosofía entre la Universidad Pontificia de Salamanca y el Institut Catholique de Paris. Ha realizado estancias de investigación en la Université Paris-Sorbonne IV, el Institut Catholique de Paris y el Institut Catholique de Toulouse. Tiene publicados numerosos artículos en revistas especializadas y ha participado como ponente en varios congresos y simposios de filosofía. Su campo de estudio e investigación se centra en la fenomenología, filosofía de la religión, teodicea, especialmente, en la fenomenología francesa contemporánea.

\section{FEDERICO TOSCA}

Federico Tosca ha realizado sus primeros estudios filosóficos en la Universidad de Pavía y ha colaborado con el profesor Luca Vanzago. Su primer trabajo de investigación se centró en El concepto de fenómeno en «Ser y Tiempo» de Heidegger. En el marco de su investigación para obtener el grado de Máster en filosofía desarrolló Intuición, expresión y forma categorial en la fenomenología de Husserl y Heidegger. Actualmente está realizando el doctorado en el programa interuniversitario FINO (Torino, Genova, Pavia, Piemonte Orientale). Su investigación doctoral desarrolla La relación entre teleología y fenomenología genética en Husserl y Enzo Paci. Por último, ha publicado algunos artículos sobre la tradición fenomenológica italiana. 